\title{
Patterns of contraceptive use among Australian women of reproductive age with chronic disease: a prospective cohort study
}

\author{
Melissa Harris ${ }^{1}$, Nicholas Egan ${ }^{2}$, Peta Forder ${ }^{1}$, Deborah Bateson $^{3}$, and Deborah Loxton ${ }^{2}$ \\ ${ }^{1}$ The University of Newcastle \\ ${ }^{2}$ University of Newcastle \\ ${ }^{3}$ Family Planning NSW
}

December 12, 2021

\begin{abstract}
Objective: Examine patterns of contraceptive use among reproductive age women, with and without chronic disease, and investigate factors which influence contraceptive use over time. Design: Population-based cohort study Setting and population: Data from 8,030 women from the Australian Longitudinal Study on Women's Health. Main outcome measures: Contraceptive patterns identified using latent transition analysis. Methods: Multinomial mixed-effect models were used to evaluate the relationship between contraceptive combinations and chronic disease. Results: Women with chronic disease used contraception at similar rates to women without chronic disease however contraceptive non-use increased over the observation period (13.6\% vs $12.7 \%$ in 2018 when aged $40-45$ years). When specific contraceptive use patterns were examined over time, differences were found for women with autoinflammatory diseases only. Compared to women without chronic disease using the pill and condoms, women with autoinflammatory disease had increased odds of using condom and natural methods $(\mathrm{OR}=1.20,95 \%$ $\mathrm{CI}=1.00,1.44)$, and sterilisation and other methods $(\mathrm{OR}=1.61,95 \% \mathrm{CI}=1.08,2.39)$ or no contraception $(\mathrm{OR}=1.32,95 \%$ $\mathrm{CI}=1.04,1.66)$, compared to women without chronic disease using short-acting methods and condoms. Conclusion: Potential gaps in the provision of appropriate contraceptive access and care exist for women with chronic disease, particularly those diagnosed with autoinflammatory conditions. Development of national guidelines as well as a clear coordinated contraceptive strategy from adolescence through to the mid reproductive years and perimenopause encouraging regular contraceptive review during care management to increase support for, and agency among, women with chronic disease is required.
\end{abstract}

Melissa L. Harris ${ }^{1,2^{*}}$, Nicholas Egan ${ }^{1,2}$, Peta M. Forder ${ }^{1,2}$, Deborah Bateson ${ }^{3,4}$, Deborah Loxton ${ }^{1,2}$

${ }^{1}$ Centre for Women's Health Research, College of Health, Medicine and Wellbeing, The University of Newcastle, Newcastle, New South Wales, Australia.

${ }^{2}$ Hunter Medical Research Institute, Newcastle, New South Wales, Australia.

${ }^{3}$ Family Planning NSW, Ashfield, New South Wales, Australia

${ }^{4}$ Discipline of Obstetrics, Gynaecology and Neonatology, Faculty of Medicine and Health, University of Sydney, Sydney, Australia

* Corresponding Author

Email: Melissa.Harris@newcastle.edu.au (Melissa L. Harris)

Running Title: Contraception and chronic disease 


\section{ABSTRACT}

Objective: Examine patterns of contraceptive use among reproductive age women, with and without chronic disease, and investigate factors which influence contraceptive use over time.

Design: Population-based cohort study

Setting and population: Data from 8,030 women from the Australian Longitudinal Study on Women's Health.

Main outcome measures: Contraceptive patterns identified using latent transition analysis.

Methods: Multinomial mixed-effect models were used to evaluate the relationship between contraceptive combinations and chronic disease.

Results: Women with chronic disease used contraception at similar rates to women without chronic disease however contraceptive non-use increased over the observation period (13.6\% vs $12.7 \%$ in 2018 when aged 40-45 years). When specific contraceptive use patterns were examined over time, differences were found for women with autoinflammatory diseases only. Compared to women without chronic disease using the pill and condoms, women with autoinflammatory disease had increased odds of using condom and natural methods $(\mathrm{OR}=1.20,95 \% \mathrm{CI}=1.00,1.44)$, and sterilisation and other methods $(\mathrm{OR}=1.61,95 \% \mathrm{CI}=1.08$, $2.39)$ or no contraception $(\mathrm{OR}=1.32,95 \% \mathrm{CI}=1.04,1.66)$, compared to women without chronic disease using short-acting methods and condoms.

Conclusion: Potential gaps in the provision of appropriate contraceptive access and care exist for women with chronic disease, particularly those diagnosed with autoinflammatory conditions. Development of national guidelines as well as a clear coordinated contraceptive strategy from adolescence through to the mid reproductive years and perimenopause encouraging regular contraceptive review during care management to increase support for, and agency among, women with chronic disease is required.

Keywords: chronic disease; contraceptive methods; long-acting reversible contraception; pill; withdrawal; women; cohort study; longitudinal

Tweetable abstract: Gaps in contraceptive care exist for women with chronic disease, particularly those with autoinflammatory conditions.

\section{INTRODUCTION}

Unintended pregnancy is highest among young women, but there is also a growing consensus that it is a significant public health issue for women of older reproductive age. ${ }^{1,2}$ In addition, the prevalence of chronic disease among women of childbearing age is on the rise. In Australia it is estimated that around $30 \%$ of women will be diagnosed with at least one chronic health condition during their reproductive years. ${ }^{3}$ This trend is predicted to increase over the coming decade, with chronic disease prevalence increasing substantially across successive generations. For women with chronic disease, unintended pregnancies are associated with serious adverse maternal and perinatal outcomes such as congenital abnormalities, spontaneous abortion, and stillbirth. ${ }^{4-7}$ Use of effective contraception is recommended as a key strategy to allow these women to plan pregnancies for times of optimal health, or to provide sufficient time to discontinue potentially teratogenic medications and switch to medications which have greater compatibility with pregnancy. However, contraceptive counselling among chronic disease populations remains low. ${ }^{8}{ }^{, 9}$ Given chronic disease is on the rise and these women report unintended pregnancy rates at similar or higher rates than the general population, understanding how they use or don't use contraception is critical to tailoring contraceptive counselling interventions for women with chronic disease as they move through their childbearing years. ${ }^{8,10,11}$

Despite this, there is limited population-level evidence regarding the contraceptive practices of women with chronic disease, and no studies have examined contraceptive patterns using nationally representative lon- 
gitudinal data. Of the few available studies, the findings have been equivocal, driven by a reliance on retrospective cross-sectional study designs, differences in contraceptive methods examined and a focus on small single disease samples. ${ }^{10,12,13}$ As such, the prevalence of contraceptive use and types of methods employed have varied widely across chronic disease populations with contraceptive use found to range from around $30 \%$ to as high as $99 \% .{ }^{14-16}$ Only one study has longitudinally examined contraceptive use among women with chronic disease of childbearing age using state-based insurance claims data. While they found only one-third of women with chronic disease were prescription contraceptive users (compared to $40 \%$ of women without a chronic condition), they were unable to examine a range of contraceptive options and they failed to account for women not at risk of pregnancy. Further, while previous studies have involved women with chronic disease across the reproductive life span, recent Australian research suggests that contraceptive patterns differ markedly by life stage and over time. ${ }^{17,18}$ It is therefore important to take a lifecourse approach to contraceptive use among women with chronic disease to understand contraceptive practices as women transition through their childbearing years. This study therefore aimed to establish an evidence-base regarding the contraceptive practices of women with chronic disease by examining patterns of contraceptive use over time among an Australian cohort of women born 1973-78 who have been prospectively followed for over 20 years.

\section{MATERNAL AND METHODS}

\section{Overview of study design}

Data were obtained from the 1973-78 cohort of the Australian Longitudinal Study on Women's Health (ALSWH), a national population-based study examining health and wellbeing among Australian women. Women were randomly sampled through the national health insurer's database (Medicare), with women from rural and remote areas sampled at twice the rates as those from urban areas to allow adequate statistical power for comparisons to be made according to geographic location. This cohort has been found to be largely representative of the population of women in this age group. ${ }^{19}$ These women have completed surveys in 1996, 2000 and then on a three-yearly schedule.

\section{Participants}

This analysis focused on women who completed Surveys 4, 6 or 8 conducted in 2006 (aged 28-33 years), 2012 (aged 34-39 years) and 2018 (aged 40-45 years). These time points provided coverage across women's main reproductive years. Of the 14,247 women who completed the baseline survey, 9,604 women were eligible for linked data analysis and completed the questions related to contraceptive use (Figure 1). At each survey, women were considered not at risk of an unintended pregnancy if they reported any of the following: no male partner, hysterectomy, currently pregnant, trying to become pregnant, infertile partner, or partner with low or zero sperm count. Excluding women who were not at risk at all time points $(\mathrm{N}=1,574)$, the final sample for analysis included 8,030 women. Women included in this analysis were similar demographically to the full 1973-78 cohort at baseline in 1996 (Supplementary Table 1).

\section{Measures}

\section{Contraceptive use}

Contraceptive patterns were derived from the question "What forms of contraception do you use now?" At each survey, contraception was measured with 14 options (with participants being able to select more than one option). Women were also asked if they had had a tubal sterilisation or if their partner had had a vasectomy. For this analysis, responses were collapsed into eight groups based on contraceptive efficacy: sterilisation (tubal sterilisation or vasectomy); Long-acting reversible contraception (LARC; the progestogen intrauterine system, the copper intrauterine device and the progestogen-only implant); short-acting hormonal 
contraception (progestogen-only contraceptive pill, combined oral contraceptive pill, oral contraception of unknown type, vaginal ring and depot injection); condoms; natural methods (withdrawal and fertility-based awareness methods); emergency oral contraception; other contraception; and no contraception. ${ }^{18}$

\section{Chronic diseases}

Chronic disease was measured by the presence or absence of seven physical chronic diseases that have been associated with poor maternal and fetal outcomes. These included diabetes, cardiac disease (including hypertension), asthma, autoinflammatory arthropathies and connective tissue disease (e.g., RA and systemic lupus erythematosus [SLE]), inflammatory bowel disease (IBD), multiple sclerosis, and thyroid disease. Chronic diseases were ascertained using multiple data sources (self-report survey, state-based hospital admissions data, pharmaceutical prescriptions and disease-specific medical claims from general practitioner and specialist care) and employing disease-specific algorithms (developed in concert with clinical experts) to increase chronic disease accuracy in this population. Detailed information on the methods employed are described elsewhere. ${ }^{20}$

\section{Covariates}

Sociodemographic variables included age, highest educational qualification (no formal qualifications, school/higher school certificate; trade/certificate/diploma; university/higher degree), area of residence (categorised according to the ARIA+ classification system as: major cities; inner regional; outer regional/remote/very remote), relationship status (partnered; unpartnered), and country of birth (Australia; other English speaking; other).

Health care card holder status (a concession card provided for government-subsidised health care) was also included as a surrogate for socioeconomic status (yes; no). Health-related factors included smoking status (current smoker; ex-smoker; non-smoker) and body mass index (underweight $\left[<18.5 \mathrm{~kg} / \mathrm{m}^{2}\right]$; healthy [[?]18.5 and $\left.<25 \mathrm{~kg} / \mathrm{m}^{2}\right]$; overweight [[?]25 and $\left.<30 \mathrm{~kg} / \mathrm{m}^{2}\right]$; obese [[?]30 $\left.\left.\mathrm{kg} / \mathrm{m}^{2}\right]\right) .{ }^{21}$

Reproductive health factors included history of pregnancy (yes; no) and history of pregnancy termination (yes; no). Given that contraception is often used for non-contraceptive reasons, the presence or absence of self-reported gynaecological conditions such as polycystic ovarian syndrome and endometriosis (yes; no) as well as the frequent experience of menstrual symptoms such as irregular periods, heavy period or severe period pain were also included (yes; no).

\section{Statistical analysis}

Chi-square analyses (for categorical variables) and independent t-tests (for continuous variables) were used to examine differences in sociodemographic and contraceptive characteristics according to chronic disease status at baseline (Survey 4) and last follow-up (Survey 8). Contraceptive data were then entered into separate latent transition models evaluating three to eight latent statuses. Establishing the optimal LTA model was conducted in a similar fashion to Harris et al. ${ }^{18}$ and was based on clinical interpretability, latent class separation and goodness-of-fit statistics. A classify-analyse approach was used to assign each participant to a latent status at each time point, according to the latent status with the greatest posterior probability. Latent transition analysis was performed using PROC LTA procedure (The Methodology Centre, Penn State) in SAS 9.4 software (SAS Institute Inc). The number of time points with latent statuses with low probabilities $(<2 \%)$ were minimised as this would contribute to numerical estimation issues in the subsequent regression models. Multinomial mixed-effect models using generalised structural equation modelling were fitted, with the assigned latent status as the multinomial outcome, and time-varying predictors. Models were developed for the presence of any chronic condition and separately for each chronic disease. We accounted for correlation between observations by treating participant as a random intercept. 


\section{RESULTS}

\section{Sample characteristics}

In $2006,25.8 \%$ of women (aged $28-33$ years) reported at least one chronic disease. This increased to $35.5 \%$ by 2018 when aged 40-45 years (Table 1). The most common chronic condition was asthma (17.9\% in 2006). Other conditions, including diabetes, cardiac disease, autoinflammatory arthropathies and connective tissue disease, IBD, multiple sclerosis, and thyroid disease each had prevalence rates of less than 5\% in 2006. However, the prevalence of each of these conditions had approximately doubled by 2018 when the women were aged 40-45 years. Given the low frequencies of autoinflammatory conditions (AICs; i.e., autoinflammatory arthropathies and connective tissue disease, IBD, multiple sclerosis, and thyroid disease) these were combined into a single autoinflammatory disease category for subsequent modelling.

Comparing women with and without chronic disease in this sample, there were few differences across sociodemographic, health behaviour and reproductive health characteristics at Survey 4 in 2006 (Table 2). Women with chronic disease were less likely to have a university degree ( $42.5 \%$ vs. $48.0 \%)$, and more likely to report their ability to manage on available income as impossible or difficult always (16.8\% vs. $11.7 \%$ ). Similar differences were also observed in 2018 when the women were aged $40-45$ years.

\section{Trends in contraceptive use}

In $2006,91.5 \%$ of women with chronic disease were using some form of contraception compared to $93.2 \%$ of women without chronic disease (Table 3 ). At this time point, $43.8 \%$ of women with chronic disease were using short-acting hormonal contraception compared to $46.2 \%$ of women without chronic disease. By 2018 , these proportions had reduced, but were still similar (15.1\% vs $15.6 \%$ ). In $2006,6.5 \%$ and $5.3 \%$ of women with and without chronic disease were using LARC, respectively. By 2018, LARC use had increased substantially with $23.7 \%$ of women with chronic disease using this method compared to $20.7 \%$ of women without chronic disease. A similar increase was noted for sterilisation methods, with relatively low use in 2006 (11.3\% vs $9.0 \%)$ and substantially higher use at age $40-45$ years in 2018 (31.6\% vs $33.0 \%)$.

Among women with chronic disease, use of one contraceptive method only was similar over time $(70.0 \%$ and $71.9 \%$ in 2006 and 2018 respectively). Use of two or more contraceptive methods declined from $21.5 \%$ in 2006 to $14.6 \%$ in 2018 . Contraceptive non-use increased over the observation period with $13.6 \%$ of women with chronic disease and $12.7 \%$ without chronic disease non-users by 2018 (when aged 40-45 years). Emergency contraception was reported with very low frequencies across time for women with and without chronic disease ( $1.6 \%$ vs $1.1 \%$ in 2006 and $0.5 \%$ vs $0.2 \%$ in 2018 , respectively). Given these low frequencies and the purpose of emergency contraception being to prevent pregnancy where contraception has not been used, misused, or has failed, it was excluded from further analysis.

\section{Contraceptive combinations}

A five-status LTA model was selected as the optimal model, given its reasonable clinical interpretability and goodness-of-fit (Supplementary Table S2). Status 1 (Table 4), "short-acting and condom" was characterised by high use of short-acting methods ( $100 \%$ predicted probability) with some supplementation with condoms (15\% predicted probability). Status 2, "condom and natural" captured high use of condoms (69\% probability) with some supplementation of non-hormonal natural methods (38\% probability) and other methods ( $8 \%$ probability). Status 3, "sterilisation and other" was dominated by vasectomy or tubal sterilisation (100\% probability) but included supplementation of other methods for some women ( $16 \%$ probability). Status 4 , "LARC" included the use of long-acting methods ( $100 \%$ probability), with a small amount of supplementation such as condoms (3\% probability). The "no contraception" status (status 5) captured the absence of contraceptive use (100\% probability). In 2006, the "short-acting and condom" was the most prevalent latent 
status including around $44 \%$ of women (Supplementary Table 3). As such, this was selected as the reference status for the subsequent multinomial regression.

\section{Contraceptive use by women with chronic disease}

There was no evidence to support a difference in the patterns of contraceptive use for women with any chronic disease compared to women without chronic disease (Table 5). When each of the chronic conditions were examined separately, a difference in contraceptive patterns was observed only for women with autoinflammatory disease. Women with autoinflammatory disease had increased odds of using condom and natural methods $(\mathrm{OR}=1.20,95 \% \mathrm{CI}=1.00,1.44)$, and sterilisation and other methods $(\mathrm{OR}=1.61,95 \% \mathrm{CI}=1.08$, 2.39 ) or no contraception $(\mathrm{OR}=1.32,95 \% \mathrm{CI}=1.04,1.66)$, compared to women without chronic disease using short-acting methods and condoms (Full model results are found in Supplementary Tables 4-8).

\section{DISCUSSION}

\section{Main findings}

By examining contraceptive combinations for women with chronic disease who were at risk of an unintended pregnancy and following these women over a 12-year observation period, we were able to provide an accurate account of contraceptive use (and non-use) for women with diabetes, cardiac disease, AICs and asthma. Although women with chronic disease used contraception at similar rates to women without chronic disease in the community, around $30 \%$ were either non-users of contraception or users of low efficacy contraception by age 40-45. However, when individual chronic diseases were examined, there was evidence to suggest that women with AICs were more likely to engage in low efficacy contraception or no contraception compared to other women. Such practices place these women at increased risk of high-risk unintended pregnancy. As such, these findings have the potential to influence the development of targeted clinical interventions and guidelines to help support provision of effective contraception for women with AICs.

\section{Strengths}

Use of nationally representative longitudinal data is a key strength of this study. We were able to examine a comprehensive set of contraceptive methods (including prescription and non-prescription methods) and applied complex statistical modelling to accurately identify contraception use (including contraceptive combinations). We also considered the dynamic nature of contraceptive use and unintended pregnancy risk across the reproductive lifecourse in our analysis. ${ }^{18,22}$ Given 5,046 women were not at risk of an unintended pregnancy for at least one of the time points, this should be standard practice for future longitudinal contraceptive research. A further strength is our approach to chronic disease measurement. ${ }^{20}$ No studies have previously employed such comprehensive methods to ascertain chronic disease among women of reproductive age or applied these to contraceptive research in the context of chronic disease.

\section{Limitations}

As we examined contraceptive use at three time points, six years apart, we were not able to identify switching of contraceptive methods in between these periods. Also, we employed a classify-analyse approach to examine changing chronic disease status as well as other key influencing factors, which potentially introduced a degree of measurement error from the latent status classification. Similar to other longitudinal cohort studies, there is an over-representation of tertiary education women in the ALSWH; however, this is the largest sample examining contraceptive patterns over time for women with chronic disease. 


\section{Interpretation}

Overall, contraceptive use among women with chronic disease in our study was found to be relatively high, with rates reported above $85 \%$ across the observation period. This finding is supported by one populationbased study but contrasts with previous cross-sectional Australian and short-term longitudinal international research (although the Australian study found similar rates between those with and without chronic disease). ${ }^{8,23,24}$ Encouragingly, there were substantial increases in the uptake of LARC and permanent methods by the time women were 40-45 years. Use of highly effective methods among women with chronic disease is supported by a previous population-based international study, although that finding was largely driven by sterilisation. ${ }^{24}$ While the use of permanent methods in our study increased over time, with around a third of women using these methods by age 40-45, almost one-quarter were using LARC by this time. This is important as these methods are safe for most women with chronic disease, have low failure rates and provide additional benefits during perimenopause. ${ }^{25}$ LARC use among women with chronic disease in this cohort however was found to be substantially lower than that reported by women with chronic disease in the 1989-95 cohort at similar ages and suggests that there may be a generational shift in the perceptions surrounding the use of LARC, including the suitability of these methods for women of reproductive age with chronic disease. ${ }^{26}$

When focused on patterns of contraceptive use across chronic disease groups, only women with AICs were found to differ in their contraceptive practices to women without chronic disease who used short-acting methods and condoms. Interestingly, method choice was complex amongst this group, with these women more likely to engage in permanent contraception or alternatively, low efficacy methods and no contraception. In this cohort, sterilisation was driven by partner vasectomy. ${ }^{18}$ For women of older reproductive age with AICs who have completed their families or do not wish to have children, this finding is promising given that partner vasectomy is a more straight forward procedure with fewer risks than female sterilisation. ${ }^{27,28}$

Concerning, however, is the increased use of low efficacy methods and non-contraceptive use among women with AICs. Previous international research has found 70-80\% of women of reproductive age with AICs were non-users of prescription contraception. ${ }^{16,23}$ Similarly, a Brazilian study found that while women with SLE were relatively high users of hormonal contraception prior to their diagnosis, more than half were non-users following their diagnosis, and for those still using contraception, it was most likely condoms. ${ }^{9}$ This is despite almost half of the women being on teratogenic medications including methotrexate. Low use of high efficacy contraception among women with AICs using fetotoxic medications has been found by others. ${ }^{29,30}$ Although condoms protect against STIs and are effective at preventing pregnancy when used consistently and correctly, given that this method requires user action with every episode of intercourse, typical contraceptive failure rates for condoms have been estimated to be around $20 \%$. The relatively low efficacy of condoms when used as a sole method of contraception limits their suitability for women with chronic disease, but when used together with a highly effective method such as a LARC or a contraceptive pill they provide protection against STIs and can increase contraceptive protection. ${ }^{31}$ However, around half of the women in our study were also predicted to combine their condom use with other low efficacy methods such as withdrawal. The layering of low efficacy methods has been demonstrated among young women, including those with AICs. ${ }^{17,26}$ This is particularly problematic as it has been found that $61 \%$ of women with SLE reported using these low efficacy methods and more than half reported having had an unintended pregnancy. ${ }^{32}$

Our findings therefore point to a lack of evidence-based advice and support from GPs and specialists. This is particularly important as our recent research has demonstrated that the use of low efficacy contraception has also been found in younger women with AICs. ${ }^{26}$ It is essential that individualised contraceptive counselling is included for women of reproductive age from the time of diagnosis and as part of their ongoing care. Switching to low efficacy methods or no contraception after an autoinflammatory diagnosis may be attributed to concerns from health professionals in relation to medical eligibility of combined oral contraceptives and certain AICs, concerns by women themselves, or both. ${ }^{33}$ Caution is warranted when prescribing estrogencontaining contraceptives to women with AICs such as RA and SLE due to the elevated risk of venous thromboembolism in those with antiphospholipid syndrome, and in those undergoing IBD-related surgery, 
while the effectiveness of oral methods will be reduced by malabsorption. ${ }^{34,35}$ LARC are ideal methods for women with AICs wishing to avoid pregnancy as they are highly effective, are not associated with an increased venous thromboembolism risk and are not impacted by malabsorption. However, misperceptions about IUDs persist, particularly regarding their suitability for young and nulliparous women and the risk of pelvic infections. ${ }^{36,37}$ The copper IUD is appropriate for women with AICs wishing to avoid hormonal methods, although its use in Australia is not currently subsidised by the federal government, unlike progestogencontaining IUDs and implant. Given copper IUDs are suitable for women of all reproductive ages including those in their forties and early fifties as well as for most women with chronic disease, subsidising the copper IUD under the PBS in Australia could facilitate uptake among women with chronic disease.

Despite increasing LARC use being a core outcome of the current Women's Health Strategy currently no formal national guidelines regarding the provision of contraception for women with chronic disease across the reproductive lifecourse exists in Australia. ${ }^{38}$ Increased access to, and awareness of current therapeutic guidelines by peak medical associations and key bodies (e.g., eTherapeutic Guidelines) as well as development of referral pathways are required alongside increasing medical education to address the demonstrated lack of expertise and confidence regarding the provision of family planning among GPs and specialists in Australia and other countries. ${ }^{39-41}$ Given the increasing prevalence of chronic disease among women of reproductive age, an embedded contraceptive strategy as part of chronic disease management could increase women's agency around contraceptive decision-making. Importantly, although women with diabetes and cardiac disease were found to be using effective contraception at rates similar to the general population, they still require regular review around the suitability of estrogen-containing contraception. As such a review of reproductive life plans should be part of best practice management for all women with chronic disease.

\section{Conclusion}

This study demonstrated that women with chronic disease take up contraception at similar rates to their same aged peers in the community, however women diagnosed with AICs were more likely to engage in low efficacy methods or no contraception. Our study highlights the potential gaps in the provision of appropriate contraceptive access and care for women with chronic disease, particularly those diagnosed with AICs. This indicates the need for the development of national guidelines as well as a clear coordinated contraceptive strategy from adolescence through to the mid reproductive years and perimenopause encouraging regular contraceptive review during care management as well as training and education for medical professionals to increase support for, and agency among, women with chronic disease. This will not only reduce the occurrence of high-risk unintended pregnancy but facilitate optimal outcomes for planned pregnancies.

\section{ACKNOWLEDGEMENTS}

The research on which this paper is based was conducted as part of the Australian Longitudinal Study on Women's Health by the University of Newcastle and the University of Queensland. We are grateful to the Australian Government Department of Health for funding and to the women who provided the survey data. The authors acknowledge the Department of Health and Medicare Australia for providing MBS and PBS data, and the Australian Institute of Health and Welfare (AIHW) as the integrating authority and also undertaking the data linkage to the National Death Index (NDI). The authors also acknowledge the following 1) Centre for Health Record Linkage (CHeReL), NSW Ministry of Health and ACT Health for the NSW Admitted Patients and ACT Admitted Patient Care Data Collections; 2) Queensland Health, including the Statistical Services Branch, for the QLD Hospital Admitted Patient Data Collection; 3) Department of Health Western Australia, including the Data Linkage Branch, and the WA Hospital Morbidity Data Collection; 4) SA NT Datalink, SA Health and the Northern Territory Department of Health, for the SA Public Hospital Separations and NT Public Hospital Inpatient Activity Data Collections; 5) The Department of Health Tasmania, and the Tasmanian Data Linkage Unit, for the Public Hospital Admitted Patient Episodes Data 
Collection; and 6) The Department of Health and Human Services Victoria, Centre for Victorian Data Linkage, for the Victorian Admitted Episodes Dataset.

\section{DISCLOSURE OF INTERESTS}

The authors have no conflict of interest to declare.

\section{AUTHOR CONTRIBUTIONS}

MLH was responsible for the study concept. MLH, NE and PMF contributed to the study design and analysis plan. NE conducted the analysis. MLH, PMF and NE contributed to case ascertainment data acquisition. MLH drafted and revised the manuscript. MLH, NE, PMF, DB, and DL reviewed the draft for intellectual content. All authors approved the final version of the paper and take responsibility for its content.

\section{ETHICS}

All data for this project were obtained from the ALSWH (see www.alswh.org.au/ for further details), approved under their Expression of Interest process (EOI A696) and provided in de-identified form. This project has ongoing ethical clearance from the University of Newcastle and University of Queensland's Human Research Ethics Committees. Ethical approval for linkage of ALSWH survey data to the Admitted Patients Data Collections (APDC) was received from the NSW Population and Health Services Research Ethics Committee and other equivalent state and territory-based committees. Linkage to the National Death Index (NDI) was approved by the Australian Institute of Health and Welfare Ethics Committee. Women provided explicit written consent to participate in the ALSWH as well as for linkage to de-identified administrative health records prior to 2005. From 2005, an 'opt-out' consent process was approved by the data custodians and relevant ethics committees for data linkage, with participants regularly reminded of this process. ALSWH participants who decline health record linkage are excluded from data linkage requests.

\section{FUNDING STATEMENT}

Dr Melissa Harris is funded through an Australian Research Council Discovery Early Career Researcher Award (DE190101134). The funding body played no role in the conduct of the research, preparation of the article or decision to submit for publication.

\section{REFERENCES}

1. Taft AJ et al. Unintended and unwanted pregnancy in Australia: a cross-sectional, national random telephone survey of prevalence and outcomes. Med J Aust. 2018;209(9):407-8.

2. Finer LB, Zolna MR. Shifts in intended and unintended pregnancies in the United States, 2001-2008. Am J Public Health. 2014;104 (Suppl 1):S43-8.

3. Miller DH et al. Pregnancy, sex and hormonal factors in multiple sclerosis. Mult Scler. 2014;20(5):527-36.

4. Bundhun PK et al. Impact of systemic lupus erythematosus on maternal and fetal outcomes following pregnancy: A meta-analysis of studies published between years 2001-2016. J Autoimmun. 2017;79:17-27. 
5. Cornish $\mathrm{J}$ et al. A meta-analysis on the influence of inflammatory bowel disease on pregnancy. Gut. 2007;56(6):830-7.

6. Macintosh MC et al. Perinatal mortality and congenital anomalies in babies of women with type 1 or type 2 diabetes in England, Wales, and Northern Ireland: population based study. BMJ. 2006;333(7560):177.

7. Khairy $\mathrm{P}$ et al. Pregnancy outcomes in women with congenital heart disease. Circulation. 2006;113(4):517-24.

8. Holton $\mathrm{S}$ et al. The fertility management experiences of Australian women with a non-communicable chronic disease: findings from the Understanding Fertility Management in Contemporary Australia Survey. Matern Child Health J. 2018;22(6):830-40.

9. Brito MB et al. Low prevalence of contraceptive use among Brazilian women of reproductive age with systemic lupus erythematosus. J Obstet Gynaecol. 2018;38(7):975-8.

10. Perritt JB et al. Contraception counseling, pregnancy intention and contraception use in women with medical problems: an analysis of data from the Maryland Pregnancy Risk Assessment Monitoring System (PRAMS). Contraception. 2013;88(2):263-8.

11. Hohmann-Marriott BE. Unplanned pregnancies of women with chronic health conditions in New Zealand. New Zealand Medical Journal. 2019;132(1499):11-7.

12. Chor $\mathrm{J}$ et al. Unintended pregnancy and postpartum contraceptive use in women with and without chronic medical disease who experienced a live birth. Contraception. 2011;84(1):57-63.

13. Chuang $\mathrm{CH}$ et al. Contraceptive use by diabetic and obese women. Womens Health Issues. 2005;15(4):167-73.

14. Gawron LM et al. Contraceptive method selection by women with inflammatory bowel diseases: a cross-sectional survey. Contraception. 2014;89(5):419-25.

15. Leverenz DL et al. Contraception methods used by women with rheumatoid arthritis and psoriatic arthritis. Clin Rheumatol. 2019;38(4):1207-12.

16. Birru Talabi $\mathrm{M}$ et al. Contraception use among reproductive-age Women with rheumatic diseases. Arthritis Care Res (Hoboken). 2018.

17. Harris ML et al. Young women's complex patterns of contraceptive use: findings from an Australian cohort study. Perspect Sex Reprod Health. 2020;52(3):181-90.

18. Harris ML et al. Contraceptive use among women through their later reproductive years: findings from an Australian prospective cohort study. PLoS One. 2021;16(8):e0255913.

19. Dobson AJ et al. Cohort Profile Update: Australian Longitudinal Study on Women's Health. Int J Epidemiol. 2015;44(5):1547,a-f.

20. Harris ML et al. Increased chronic disease prevalence among the younger generation: findings from a population-based data linkage study to inform chronic disease ascertainment among reproductive-aged Australian women. PLoS One. 2021;16(8):e0254668.

21. World Health Organization. Obesity: preventing and managing the global epidemic: a report of a WHO consultation. Geneva, Switzerland: WHO; 2000.

22. Jones RK et al. Using longitudinal data to understand changes in consistent contraceptive use. Perspectives on Sexual and Reproductive Health. 2015;47(3):131-9.

23. DeNoble AE et al. Receipt of prescription contraception by commercially insured women with chronic medical conditions. Obstet Gynecol. 2014;123(6):1213-20. 
24. Phillips-Bell GS et al. Chronic diseases and use of contraception among women at risk of unintended pregnancy. J Womens Health (Larchmt). 2016;25(12):1262-9.

25. Bateson D, McNamee K. Perimenopausal contraception: a practice-based approach. Aust Fam Physician. 2017;46(6):372-7.

26. Harris ML et al. Patterns of contraceptive use among young Australian women with chronic disease: findings from a prospective cohort study [preprint]. Research Square. 2021.

27. Lincoln E et al. Male and female sterilisation. Obstet Gynaecol Reprod Med. 2020;30(7):219-24.

28. Richters J et al. Contraceptive practices among women: the second Australian study of health and relationships. Contraception. 2016;94(5):548-55.

29. Birru Talabi M et al. Family planning counseling for women with rheumatic diseases. Arthritis Care Res (Hoboken). 2018;70(2):169-74.

30. Yazdany J et al. Contraceptive counseling and use among women with systemic lupus erythematosus: a gap in health care quality? Arthritis Care Res (Hoboken). 2011;63(3):358-65.

31. Trussell J. Understanding contraceptive failure. Best Pract Res Clin Obstet Gynaecol. 2009;23(2):199209.

32. Dalkilic E et al. Comparing female-based contraceptive methods in patients with systemic lupus erythematosus, rheumatoid arthritis and a healthy population. Int J Rheum Dis. 2014;17(6):653-7.

33. Faculty of Sexual and Reproductive Healthcare Clinical Effectiveness Unit. Faculty of Sexual and Reproductive Healthcare Clinical Guidance Report. UK: FSRH; 2014.

34. Zapata LB et al. Contraceptive use among women with inflammatory bowel disease: a systematic review. Contraception. 2010;82(1):72-85.

35. Fumery M et al. Thromboembolic events and cardiovascular mortality in inflammatory bowel diseases: a meta-analysis of observational studies. J Crohns Colitis. 2014;8(6):469-79.

36. Tepper NK et al. Safety of intrauterine devices among women with HIV: a systematic review. Contraception. 2016;94(6):713-24.

37. Farr SL et al. Safety of contraceptive methods for women with rheumatoid arthritis: a systematic review. Contraception. 2010;82(1):64-71.

38. Australian Government Department of Health. National women's health strategy: 2020-2030. Canberra: Commonwealth of Autralia; 2020.

39. Toomey D, Waldron B. Family planning and inflammatory bowel disease: the patient and the practitioner. Fam Pract. 2013;30(1):64-8.

40. Mazza D et al. Barriers to the implementation of preconception care guidelines as perceived by general practitioners: a qualitative study. BMC Health Serv Res. 2013;13:36.

41. eTG complete [digital]. Melbourne: Therapeutic Guidelines Limited; 2020 Dec.

Figure 1. Determination of eligible sample.

Table 1. Proportion of women with chronic disease over the observation period.

\begin{tabular}{llll}
\hline & 2006 Aged 28-33 & 2012 Aged 34-39 & 2018 Aged 40-45 \\
Chronic disease & $\mathbf{N = 5 , 4 0 2}$ & $\mathbf{N = 5 , 0 9 2}$ & $\mathbf{N = 4 , 6 6 0}$ \\
\hline & $\mathbf{n}(\%)$ & $\mathbf{n ~ ( \% )}$ & $\mathbf{n}(\%)$ \\
Any physical chronic & $1,394(25.8)$ & $1,636(32.1)$ & $1,656(35.5)$ \\
disease & & &
\end{tabular}




\begin{tabular}{|c|c|c|c|}
\hline Chronic disease & $\begin{array}{l}2006 \text { Aged } 28-33 \\
N=5,402\end{array}$ & $\begin{array}{l}2012 \text { Aged } 34-39 \\
\mathrm{~N}=5,092\end{array}$ & $\begin{array}{l}2018 \text { Aged } 40-45 \\
\mathrm{~N}=4,660\end{array}$ \\
\hline Diabetes & $144(2.7)$ & $210(4.1)$ & $246(5.3)$ \\
\hline Cardiac disease & $260(4.8)$ & $396(7.8)$ & $430(9.2)$ \\
\hline Asthma & $965(17.9)$ & $928(18.2)$ & $883(18.9)$ \\
\hline $\begin{array}{l}\text { a Autoinflammatory } \\
\text { disease }\end{array}$ & $276(5.1)$ & $469(9.2)$ & $510(10.9)$ \\
\hline Arthropathies & $97(1.8)$ & $150(2.9)$ & $186(4.0)$ \\
\hline $\begin{array}{l}\text { Inflammatory bowel } \\
\text { disease }\end{array}$ & $28(0.5)$ & $40(0.8)$ & $53(1.1)$ \\
\hline Thyroid disease & $45(0.8)$ & $155(3.0)$ & $194(4.2)$ \\
\hline Multiple sclerosis & $85(1.6)$ & $120(2.4)$ & $116(2.5)$ \\
\hline${ }^{\mathrm{a}}$ Includes & ${ }^{\mathrm{a}}$ Includes & ${ }^{\mathrm{a}}$ Includes & ${ }^{\text {a Includes }}$ \\
\hline autoinflammatory & autoinflammatory & autoinflammatory & autoinflammatory \\
\hline arthropathies, & arthropathies, & arthropathies, & arthropathies, \\
\hline inflammatory bowel & inflammatory bowel & inflammatory bowel & inflammatory bowel \\
\hline disease, thyroid disease & disease, thyroid disease & disease, thyroid disease & disease, thyroid disease \\
\hline and multiple sclerosis. & and multiple sclerosis. & and multiple sclerosis. & and multiple sclerosis. \\
\hline
\end{tabular}

Table 2:Characteristics of women from the 1973-78 cohort at Survey 4 in 2006 (aged 28-33 years), according to chronic disease status $(n=5,402)$.

\begin{tabular}{|c|c|c|c|}
\hline Characteristic & Category & Chronic disease status & Chronic disease stat \\
\hline & & Absent $\mathrm{n}=4,008 \mathrm{n}(\%)$ & Present $\mathrm{n}=1,394 \mathrm{n}($ \\
\hline \multicolumn{4}{|l|}{ Sociodemographics } \\
\hline \multirow[t]{4}{*}{ Country of birth } & Australia & $3,548(88.5)$ & $1,264(90.7)$ \\
\hline & Other English-speaking background & $181(4.5)$ & $69(4.9)$ \\
\hline & Non-English-speaking background & $261(6.5)$ & $58(4.2)$ \\
\hline & Missing & $18(0.4)$ & $3(0.2)$ \\
\hline \multirow[t]{4}{*}{ Area of residence } & Major cities & $2,301(57.4)$ & $763(54.7)$ \\
\hline & Inner regional & $985(24.6)$ & $401(28.8)$ \\
\hline & Outer regional/remote/very remote & $722(18.0)$ & $230(16.5)$ \\
\hline & Missing & $0(0.0)$ & $0(0.0)$ \\
\hline \multirow[t]{5}{*}{ Education } & No formal qualifications & $30(0.7)$ & $23(1.6)$ \\
\hline & School certificate/higher school certificate & $986(24.6)$ & $361(25.9)$ \\
\hline & Trade/apprentice/certificate/diploma & $1,056(26.3)$ & $412(29.6)$ \\
\hline & University/higher degree & $1,925(48.0)$ & $593(42.5)$ \\
\hline & Missing & $11(0.3)$ & $5(0.4)$ \\
\hline \multirow[t]{3}{*}{ Relationship status } & Partnered & $3,228(80.5)$ & $1,092(78.3)$ \\
\hline & Unpartnered & $768(19.2)$ & $296(21.2)$ \\
\hline & Missing & $12(0.3)$ & $6(0.4)$ \\
\hline \multirow[t]{3}{*}{ Health care card } & No & $3,520(87.8)$ & $1,137(81.6)$ \\
\hline & Yes & $486(12.1)$ & $256(18.4)$ \\
\hline & Missing & $2(0.1)$ & $1(0.1)$ \\
\hline \multicolumn{4}{|l|}{ Health factors } \\
\hline \multirow[t]{4}{*}{ Smoking } & Non-smoker & $2,336(58.3)$ & $760(54.5)$ \\
\hline & Ex-smoker & $870(21.7)$ & $303(21.7)$ \\
\hline & Current smoker & $783(19.5)$ & $326(23.4)$ \\
\hline & Missing & $19(0.5)$ & $5(0.4)$ \\
\hline Body mass index & Underweight & $137(3.4)$ & $31(2.2)$ \\
\hline
\end{tabular}




\begin{tabular}{|c|c|c|c|}
\hline Characteristic & Category & Chronic disease status & Chronic disease statı \\
\hline & Healthy & $2,329(58.1)$ & $646(46.3)$ \\
\hline & Overweight & $910(22.7)$ & $359(25.8)$ \\
\hline & Obese & $535(13.3)$ & $318(22.8)$ \\
\hline & Missing & $97(2.4)$ & $40(2.9)$ \\
\hline \multicolumn{4}{|l|}{ Reproductive health } \\
\hline \multirow[t]{3}{*}{ History of pregnancy } & No & $3,458(86.3)$ & $1,186(85.1)$ \\
\hline & Yes & $526(13.1)$ & $204(14.6)$ \\
\hline & Missing & $24(0.6)$ & $4(0.3)$ \\
\hline \multirow[t]{3}{*}{ History of termination } & No & $3,320(82.8)$ & $1,118(80.2)$ \\
\hline & Yes & $687(17.1)$ & $275(19.7)$ \\
\hline & Missing & $1(0.0)$ & $1(0.1)$ \\
\hline \multirow[t]{5}{*}{ Parity } & Zero & $1,833(45.7)$ & $621(44.5)$ \\
\hline & One & $797(19.9)$ & $292(20.9)$ \\
\hline & Two & $975(24.3)$ & $345(24.7)$ \\
\hline & Three or more & $403(10.1)$ & $136(9.8)$ \\
\hline & Missing & $0(0.0)$ & $0(0.0)$ \\
\hline \multirow[t]{3}{*}{ Menstrual symptoms } & No & $3,397(84.8)$ & $1,105(79.3)$ \\
\hline & Yes & $580(14.5)$ & $283(20.3)$ \\
\hline & Missing & $31(0.8)$ & $6(0.4)$ \\
\hline \multirow[t]{3}{*}{ History of PCOS* } & No & $3,942(98.4)$ & $1,352(97.0)$ \\
\hline & Yes & $66(1.6)$ & $42(3.0)$ \\
\hline & Missing & $0(0.0)$ & $0(0.0)$ \\
\hline \multirow[t]{3}{*}{ History of endometriosis } & No & $3,893(97.1)$ & $1,342(96.3)$ \\
\hline & Yes & $115(2.9)$ & $52(3.7)$ \\
\hline & Missing & $0(0.0)$ & $0(0.0)$ \\
\hline
\end{tabular}

*PCOS = Polycystic ovary syndrome

Table 3. Contraceptive trend over time by chronic disease status.

\begin{tabular}{|c|c|c|c|c|}
\hline Contraception & $\begin{array}{l}\text { Chronic } \\
\text { disease status } \\
2006 \text { (Survey } \\
\text { 4) Aged 28-33 } \\
\text { years }\end{array}$ & $\begin{array}{l}\text { Chronic } \\
\text { disease status } \\
2006 \text { (Survey } \\
\text { 4) Aged 28-33 } \\
\text { years }\end{array}$ & $\begin{array}{l}\text { Chronic } \\
\text { disease status } \\
2018 \text { (Survey } \\
\text { 8) Aged 40-45 } \\
\text { years }\end{array}$ & $\begin{array}{l}\text { Chronic } \\
\text { disease status } \\
2018 \text { (Survey } \\
\text { 8) Aged 40-45 } \\
\text { years }\end{array}$ \\
\hline & $\begin{array}{l}\text { No } n=4,008 \\
n(\%)\end{array}$ & $\begin{array}{l}\text { Yes } n=1,394 \\
\text { n }(\%)\end{array}$ & $\begin{array}{l}\text { No } n=3,004 \\
\text { n }(\%)\end{array}$ & $\begin{array}{l}\text { Yes } n=1,656 \\
n(\%)\end{array}$ \\
\hline Condom & $1,297(32.4)$ & $423(30.3)$ & $534(17.8)$ & $261(15.8)$ \\
\hline Short acting ${ }^{\mathrm{A}}$ & $1,853(46.2)$ & $611(43.8)$ & $455(15.1)$ & $259(15.6)$ \\
\hline $\mathrm{LARC}^{\mathrm{B}}$ & $213(5.3)$ & $91(6.5 \%)$ & $622(20.7)$ & $393(23.7)$ \\
\hline $\begin{array}{l}\text { Natural } \\
\text { methods }\end{array}$ & $503(12.5)$ & $172(12.3)$ & $337(11.2)$ & $177(10.7)$ \\
\hline $\begin{array}{l}\text { No } \\
\text { contraception }\end{array}$ & $271(6.8)$ & $118(8.5)$ & $382(12.7)$ & $225(13.6)$ \\
\hline
\end{tabular}




\begin{tabular}{|c|c|c|c|c|c|}
\hline Contraception & & $\begin{array}{l}\text { Chronic } \\
\text { disease status } \\
2006 \text { (Survey } \\
\text { 4) Aged 28-33 } \\
\text { years }\end{array}$ & $\begin{array}{l}\text { Chronic } \\
\text { disease status } \\
2006 \text { (Survey } \\
\text { 4) Aged 28-33 } \\
\text { years }\end{array}$ & $\begin{array}{l}\text { Chronic } \\
\text { disease status } \\
2018 \text { (Survey } \\
\text { 8) Aged 40-45 } \\
\text { years }\end{array}$ & $\begin{array}{l}\text { Chronic } \\
\text { disease status } \\
2018 \text { (Survey } \\
\text { 8) Aged 40-45 } \\
\text { years }\end{array}$ \\
\hline \multirow{4}{*}{$\begin{array}{l}\text { Number of } \\
\text { contraceptives }\end{array}$} & 0 & $271(6.8)$ & $118(8.5)$ & $382(12.7)$ & $225(13.6)$ \\
\hline & 1 & $2,962(73.9)$ & $976(70.0)$ & $2,204(73.4)$ & $1,191(71.9 \%)$ \\
\hline & 2 & $713(17.8)$ & $280(20.1)$ & $404(13.4)$ & $228(13.8 \%)$ \\
\hline & $3+$ & $62(1.5)$ & $20(1.4)$ & $14(0.5)$ & $12(0.7 \%)$ \\
\hline
\end{tabular}

A The short-acting category was composed of the pill (91.5\%), the minipill (5.8\%), injection (2.5\%) and vaginal ring $(0.7 \%)$.

B The long-acting reversible contraception (LARC) category was composed of progestogen-only IUD (64.5\%), implant $(32.2 \%)$ and copper IUD $(4.0 \%)$.

$\mathrm{C}$ The natural methods category was composed of withdrawal method (88.9\%) and fertility awareness methods $(20.1 \%)$.

D The sterilisation category was composed of vasectomy (79.1\%) and tubal ligation (21.6\%).

Note: Types of contraception do not add to $100 \%$ as respondents were able to select multiple methods

$\mathrm{LARC}=$ long-acting reversible contraception.

Table 4. Five-status model for contraceptive patterns over time for the 1973-78 ALSWH cohort.

\begin{tabular}{llll}
\hline Latent Status & Latent status description & Item-response probabilities for each status & Item-response prob \\
\hline & & Condom & Short-acting \\
Status 1 & Short-acting and condom & 0.15 & 1.00 \\
Status 2 & Condom and natural & 0.69 & 0.04 \\
Status 3 & Sterilisation and other & 0.02 & 0.04 \\
Status 4 & LARC & 0.03 & - \\
Status 5 & No contraception & - & - \\
\hline
\end{tabular}

Note: Dashed cells have probability $<0.01$. Shaded status (\#1, short-acting and condom) was selected as the reference class for subsequent analysis.

Natural methods $=$ withdrawal and fertility-awareness methods.

LARC $=$ Long-acting reversible contraception.

Table 5. Multinomial mixed-effect models for the effect of chronic disease status on contraceptive use for Australian women, aged 28 to 45 across three time points (2006, 2012 \& 2018). 


\begin{tabular}{|c|c|c|c|c|c|c|c|c|c|}
\hline Model & $\begin{array}{l}\text { Chronic } \\
\text { disease } \\
\text { status }\end{array}$ & $\begin{array}{l}\text { Condom } \\
\& \\
\text { natural } \\
\text { OR }(95 \% \\
\text { CI) }\end{array}$ & $\mathrm{P}$ & $\begin{array}{l}\text { Steri } \\
\& \text { ot } \\
\text { OR } \\
\text { CI) }\end{array}$ & $\mathrm{P}$ & $\begin{array}{l}{ }^{\mathrm{a}} \mathrm{LARC} \\
\text { OR }(95 \% \\
\text { CI })\end{array}$ & $\mathrm{P}$ & $\begin{array}{l}\text { None OR } \\
(95 \% \text { CI })\end{array}$ & $P$ \\
\hline 1 & $\begin{array}{l}\text { Any } \\
\text { physi- } \\
\text { cal } \\
\text { chronic } \\
\text { disease }\end{array}$ & $\begin{array}{l}0.97 \\
(0.88, \\
1.08)\end{array}$ & 0.62 & $\begin{array}{l}1.23 \\
(0.96, \\
1.57)\end{array}$ & 0.10 & $\begin{array}{l}1.12 \\
(0.96, \\
1.32)\end{array}$ & 0.15 & $\begin{array}{l}1.07 \\
(0.93 \\
1.23)\end{array}$ & c \\
\hline 2 & $\begin{array}{l}\text { Cardiac } \\
\text { disease }\end{array}$ & $\begin{array}{l}0.86 \\
(0.67, \\
1.10)\end{array}$ & 0.11 & $\begin{array}{l}0.79 \\
(0.52, \\
1.20)\end{array}$ & 0.26 & $\begin{array}{l}1.03 \\
(0.78, \\
1.34)\end{array}$ & 0.85 & $\begin{array}{l}0.86 \\
(0.67, \\
1.10)\end{array}$ & \\
\hline 3 & Diabetes & $\begin{array}{l}1.28 \\
(0.95, \\
1.74)\end{array}$ & 0.57 & $\begin{array}{l}0.84 \\
(0.48, \\
1.47)\end{array}$ & 0.54 & $\begin{array}{l}1.34 \\
(0.95 \\
1.91)\end{array}$ & 0.10 & $\begin{array}{l}1.28 \\
(0.95, \\
1.74)\end{array}$ & \\
\hline 4 & Asthma & $\begin{array}{l}1.00 \\
(0.85, \\
1.18)\end{array}$ & 0.97 & $\begin{array}{l}1.14 \\
(0.84, \\
1.54)\end{array}$ & 0.41 & $\begin{array}{l}1.04 \\
(0.86, \\
1.26)\end{array}$ & 0.69 & $\begin{array}{l}1.00 \\
(0.85, \\
1.18)\end{array}$ & \\
\hline 5 & $\begin{array}{l}\text { Autoinflar } \\
\text { disease }\end{array}$ & $\begin{array}{l}(1.04, \\
1.66)\end{array}$ & 0.04 & $\begin{array}{l}1.61 \\
(1.08, \\
2.39)\end{array}$ & 0.02 & $\begin{array}{l}1.18 \\
(0.91,1.53)\end{array}$ & 0.21 & $\begin{array}{l}1.32 \\
(1.04, \\
1.66)\end{array}$ & \\
\hline
\end{tabular}

Reference status $=$ short-acting and condom; reference level for disease $=$ disease not present.

Each model controlled for age, country of birth, area of residence, highest educational qualification, relationship status, health care card holder status, smoking status, body mass index, history of pregnancy, history of termination, history of miscarriages, menstrual symptoms, history of polycystic ovary syndrome, history of endometriosis, and survey wave.

LARC $=$ Long-acting reversible contraception.

Full model results can be found in Supplementary Tables 4-8. 